\title{
Merawat Harmoni Agama melalui Kolaborasi Musik Hadroh dan Trompet di Ambon
}

\section{Dewi Tika Lestari*}

Institut Agama Kristen Negeri Ambon, Indonesia; dewitikalestari85@gmail.com

* Correspondence

Received: 2020-06-23; Accepted: 2020-08-04; Published: 2020-08-29.

\begin{abstract}
This article aims to describe the role of music for preserving religious harmony after the social-religious conflict that occurred in 1999-2004 in Maluku. The study is conducted toward the collaboration of musicians of the music of hadroh which come from the Muslim community and the music of trumpet which come from the Christian community in Ambon City. This study uses a qualitative research approach with a discourse analysis approach. The study shows that both of the musical instruments, hadroh and trumpet, are always used in religious rituals, both in Islam and Christian. The musicians are also fromthese two religions. This study also found that Muslim and Christian can collaborate to provide a new style and introduce a new approach for maintaining peace in Maluku. As a result, this study shows that music has the power to preserve peace in a pluralistic society.
\end{abstract}

Keywords: Hadroh; Maluku; Music; Religious Harmony; Trumpets.

Abstrak: Kajian ini bertujuan untuk menggambarkan peranan musik dalam melestarikan perdamaian antar umat beragama di Maluku pasca konflik sosial yang pernah terjadi pada tahun 1999-2004. Penelitian dilakukan terhadap aktivitas para musisi yang mengkolaborasikan musik hadroh dari masyarakat Muslim dengan musik trompet dari masyarakat Kristen di Kota Ambon. Dua instrument musik ini digunakan dalam ritual keagamaan Islam dan Kristen. Para musisinya juga dari agama yang berbeda. Namun, mereka dapat berkolaborasi dan memberikan suatu corak baru dalam merawat perdamaian di Maluku. Penelitian ini menggunakan pendekatan penelitian kualitatif deskriptif dengan menggunakan pendekatan analisis diskursus. Hasilnya, kajian ini menunjukkan bahwa music memiliki kekuatan untuk melestarikan perdamaian dalam masyarakat majemuk.

Kata Kunci: Hadroh; Harmoni Agama; Maluku; Musik; Trompet.

\section{Pendahuluan}

Kajian mengenai proses merawat perdamaian antar umat beragama di Maluku, terutama di kota Ambon, pasca konflik 1999-2004 telah banyak dihasilkan dan dipublikasikan. Perdamaian antar umat beragama di Maluku telah menjadi semacam laboratorium atau bisa juga disebut museum (Tahalea, Tondobala, \& Mastutie, 2016), tempat belajar merawat harmoni antar umat beragama. Beberapa studi mengenai perdamaian di Maluku yang telah dilakukan, antara lain dari perspektif budaya lokal (Iwamony, Gaspersz, \& Souisa, 2019; Parihala, Samson, \& Tika Lestari, 2019; Tiwery, 2018), dari pendekatan studi sosiologis dan antropologis (Dandirwalu, 2016; Ernas, 2018; Iwamony et al., 2019; Lestari \& Parihala, 2020a; Mannitz, 2017; T. Pariela, 2008), ada juga dari pendekatan studi agamaagama (Al Qurtuby, 2013; Diah Kusumaningrum, 2017; Lalopua \& Iwamony, 2019; Parihala \& Sapteno, 2020; Sabandar, Saimima, \& Parihala, 2020). Dalam kaitan dengan proses merawat perdamaian di Maluku, kajian ini menggambarkan perspektif baru, bahwa kolaborasi musik juga dapat berkontribusi membangun hubungan yang harmonis antar umat beragama di Maluku. Aktivitas para musisi dengan kreasi musikal yang harmonis antara musik hadroh milik umat Muslim dan trompet milik umat Kristen di kota Ambon telah menggambarkan peran serta musik dalam memelihara perdamaian di Maluku. Bagaimanapun proses merawat harmoni di antara umat beragama di Maluku masih sangat 
dibutuhkan, terutama ketika memori konflik yang pernah dialami masih tetap hidup di dalam memori kolektif masyarakat Maluku (Lestari, 2019; Lestari \& Parihala, 2020).

Masyarakat Maluku yang sekarang hidup dalam situasi perdamaian pasca konflik, masih menyimpan dalam memori kolektif mereka, realitas konflik yang memilukan itu. Hal ini disebabkan oleh pengalaman kolektif terkait berbagai dampak destruktif akibat konflik Maluku. Konflik Maluku telah menimbulkan dampak negatif yang berimplikasi pada berbagai aspek kehidupan masyarakat. Trijono menjelaskan bahwa konflik Maluku menimbulkan dampak kerusakan yang hebat di tengah komunitas masyarakat Maluku. Dampak konflik tersebut, antara lain menimbulkan korban kekerasan langsung, yaitu ribuan nyawa yang melayang, ribuan orang terluka dan ada yang cacat tubuh seumur hidup, ditambah dengan masyarakat Maluku yang menjadi pengungsi di tanah sendiri. Selain itu, ada pula dampak konflik tidak langsung, seperti kerusakan bangunan atau kerusakan fisik, kerusakan hubungan sosial masyarakat, krisis perekonomian dan menajamnya segregasi sosial masyarakat (Trijono, 2001).

Dalam aspek sosial budaya, konflik telah menciptakan pemilahan sosial dan mempertajam segregasi kelompok berdasarkan garis keagamaan (Kalay, 2020; Lestari \& Parihala, 2020), yang disertai menguatnya sentimen solidaritas kelompok. Kondisi ini semakin diperkuat dengan terbentuknya pemukiman-pemukiman segregasi sebagai akibat dari gelombang pengungsian masyarakat yang menjadi korban konflik. Sebelum konflik masih ditemukan pemukiman masyarakat yang berbaur dan hidup bersama pada satu tempat sekalipun berbeda agama. Namun konflik telah memaksa masyarakat yang "kalah" atau "sedikit jumlahnya" untuk secara terpaksa pindah meninggalkan tempat hunian dan rumah kehidupan mereka (Lindawaty, 2016; Palmer, 2014). Untuk menyelamatkan diri, para pengungsi ini kemudian direlokasi ke wilayah pemukiman masyarakat yang memiliki kesamaan agama.

Maluku sekarang telah damai. Masyarakat dapat menjalani aktivitas sosial secara bersama. Pemerintah dan masyarakat Maluku terus berupaya memelihara proses damai yang telah ada. Salah satu pendekatan yang mengisi sejarah merawat perdamaian di Maluku adalah aktivitas kolaborasi musik trompet dan musik hadroh dari dua komunits masyarakat, yang dahulu saling berperang dan bermusuhan dalam peristiwa konflik Maluku.

Paduan trompet Jemaat Gereja Protestan Maluku (GPM) Rehobot bersama komunitas musik hadroh Masjid Waringin-Talake, telah menjalin suatu kolaborasi dan harmonisasi musikal dalam rangka merawat perdamaian di kedua wilayah tersebut. Kedua masyarakat di wilayah Batugantung dan Waringin telah merajut kembali harmoni sosial dan kedamaian. Untuk merawat harmoni sosial dan situasi damai, kedua komunitas yang berbeda agama ini mewujudkan peran bersama melalui harmonisasi musik trompet dari warga jemaat GPM Rehobot dengan musik hadroh dari komunitas Muslim Waringin. Kolaborasi musik kedua komunitas ini bahkan telah diapresiasi oleh pemerintah daerah, tokoh agama, dan warga masyarakat, karena mampu mewujudkan dan merawat harmoni dan perdamaian Maluku.

Konteks merawat harmoni ini penting untuk dianalisis melalui analisis diskursus untuk mengkonstruksikan makna dan wacana perdamaian yang dapat dikomunikasikan kepada publik. Untuk itu, kajian ini menggunakan metode penelitian kualitatif. Menurut Sugiyono, metode ini disebut juga metode artistik, karena proses penelitian lebih bersifat seni, dan disebut juga metode interpretative karena data hasil penelitian dianalisis melalui proses interpretasi untuk menemukan makna. Dalam studi ini, penelitian kualitatif dilakukan dengan mengedapankan dua hal yang ingin dicapai, yaitu: (1) menganalisis proses berlangsungnya kolaborasi musik hadroh dan trompet dari umat Islam dan Kristen di Maluku. Selanjutnya, (2) menganalisis wacana dan makna merawat harmoni antar umat beragama yang ada di balik fenomena tersebut.

\section{Analisis Wacana Harmoni Agama Melalui Harmoni Musik}

Ada dua unsur yang berperan dalam kajian merawat damai melalui harmoni musik trompet dan hadroh, yakni unsur musik dan interkasi sosial. Dalam hal ini, Bergh \& Sloboda (2010) pernah mengkaji suatu penelitian sosiologi yang mendalami peran musik dalam transformasi konflik di Norwegia dan 
Sudan. Dalam kajiannya, Bergh (2010) menemukan bahwa musik memiliki kekuatan dalam transformasi konflik jika diposisikan sebagai suatu ativitas sosial. Dalam aktivitas sosialnya, musik berisikan sejumlah isu dan kepentingan sosiologis, seperti transformasi konflik, pengembangan jejaring sosial, hubungan kekuasan lintas ruang, komunikasi lintas budaya, dan konstruksi identitas kultural melalui penemuan kembali tradisi masa lampau.

Dalam studi ini, analisis wacana menggunakan model analisis yang dikembangkan oleh Norman Fairclough melalui pendekatan yang disebutnya sebagai Critical Discourse Analysis (Analisa Wacana Kritis). Critical Discourse Analysis ini dikembangkan dari perangkat analisis di dalam teori-teori linguistik dan sosiologis, dengan tujuan utamanya agar suatu wacana tidak dipahami hanya sekedar dengan mengeksplorasi aspek-aspek kebahasaan, tetapi juga investigasi konteks sosiologis. Dengan demikian, maka kita akan menemukan makna yang utuh dari suatu wacana dan bagaimana ia digunakan di dalam masyarakat. Menurut Fairclough, suatu wacana dianggap memiliki peran penting dalam membentuk masyarakat. Dalam perspektifnya, wacana tidak hanya terbatas dalam bentuk tertulis, tetapi juga meliputi bentuk lisan dan tindakan. Ia tidak hanya digunakan untuk merepresentasi masyarakat, tetapi juga turut merekonstruksi masyarakat sesuai dengan kepentingan ideologis tertentu. Di dalam setiap wacana, baik individu maupun sosial, terdapat ideologi tertentu yang lahir dari kompleksitas relasi yang terjadi di dalam masyarakat. Ideologi ini kemudian dihadirkan melalui wacana, berdialektika dengan ideologi lain sehingga proses hegemoni terjadi, dan akhirnya turut membentuk ulang suatu realitas sosial. Menurutnya, suatu wacana memiliki paling tidak tiga fungsi, yakni mengkonstruksi identitas, mengatur posisi dan hubungan sosial, dan mentransfer suatu keyakinan atau pengetahuan. Dalam mengungkapkan fungsi-fungsi diskursif ini, Fairclough mengajak kita untuk fokus pada aspek bahasa, praktek wacana, dan praktek sosial (Fairclough, 2013).

Dalam kajian disertasinya, Lestari menemukan bahwa wacana dan realitas perdamaian, mampu dikontruksikan dan dikomunikasikan melalui peran musik yang menghidupkan memori kolektif masyarakat Maluku sebagai sesama orang basudara. Memori itu kemudian membangkitkan kembali wacana terkait identitas kolektif masyarakat Maluku yang berada di dalam pengalaman konflik bahwa sesungguhnya mereka adalah sesama orang basudara. Dari sinilah, praksis sosial terkait proses diplomasi untuk membangun perdamaian terus terbangun sehingga terwujudlah kembali realitas damai dalam konflik di Maluku (Lestari, 2017).

\section{Mengenali Musik Hadroh dan Trompet}

Kesenian hadroh merupakan kesenian Islam yang di dalamnya dilantunkan syair-syair dengan tabuhan-tabuhan oleh alat-alat rebana yang khas. Syair atau nyanyian religius adalah nyanyian yang dihubungkan dengan nuansa keagamaan. Agama merupakan tujuan dan isi dari nyanyian tersebut. Oleh karena itu nyanyian religius ini syair-syairnya hanya menceritakan kebesaran Al-Qur'an, kecintaan kepada Allah SWT, Rasulullah SAW, orang-orang saleh dari hamba Allah, kehidupan akhirat dan kenikmatan surga yang menceritakan makna ketuhanan dan keimanan yang dibawa oleh Rasulullah SAW (Sholikha, 2018).

Hadroh adalah kesenian Islam yang di dalamnya berisi shalawat Nabi Muhammad SAW untuk mensyiarkan ajaran agama Islam, dalam kesenian ini tidak ada alat musik lain kecuali rebana. Keunikan alat musik rebana yang digunakan dalam kesenian hadrah ini, khususnya adalah pada saat memainkannya. Setiap pukulan pemain satu dengan pemain yang lain berbeda. Namun mereka saling melengkapi. Nada-nada yang dihasilkan rebana memang berbeda, tapi justru itulah yang membentuk harmoni bermusik. Jadi, setiap pemain harus mengontrol egonya agar ritmis nada tetap terjaga dan tidak merusak pakem nada (Sholikha, 2018).

Instrumen musik hadroh secara tekniknya tergolong jenis instrumen musik ritmis. Alat musik ritmis merupakan alat musik yang tidak memiliki nada dan alat musik ini dimainkan dengan cara dipukul. Bagian yang dipukul, pada umumnya dibuat dari kulit kambing atau kulit sapi (membranphone). Untuk konstruksinya sendiri, instrument ini dibuat dari kayu, berbentuk lingkaran pipih dengan diameter bervariasi antara 25 sampai dengan $30 \mathrm{~cm}$. Walaupun instrument membraphone ini tidak bernada, tetapi ia dapat menciptakan harmoni yang indah. Di Indonesia pada umumnya, alat 
musik hadroh disebut dengan nama rebana. Namun, warga dan pemain musik hadrah Talake menyebutnya dengan istilah tifa. Sebutan ini mengikuti kebiasaan masyarakat Maluku, yang menyebutkan alat musik yang terbuat dari selaput kulit hewan dengan istilah tifa. Untuk alat musik tifa yang digunakan terdiri dari empat jenis, yaitu tifa jalang yang digunakan untuk mengatur tempo dan menjadi pukulan dasar atau intro, tifa cincang bawah, tifa cincang atas, dan tifa ropol. Gambar 1 adalah jenis tifa musik hadroh Talake.

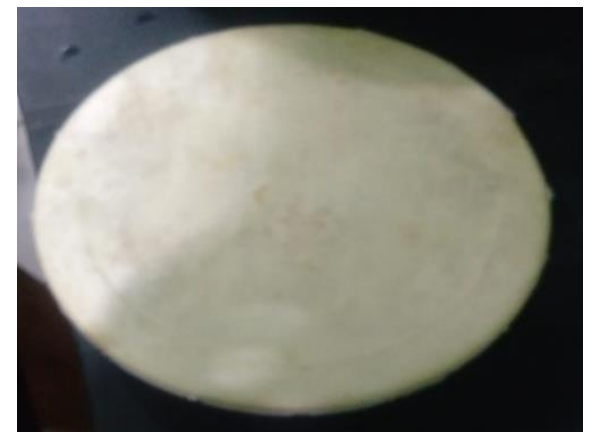

Tifa Jalang

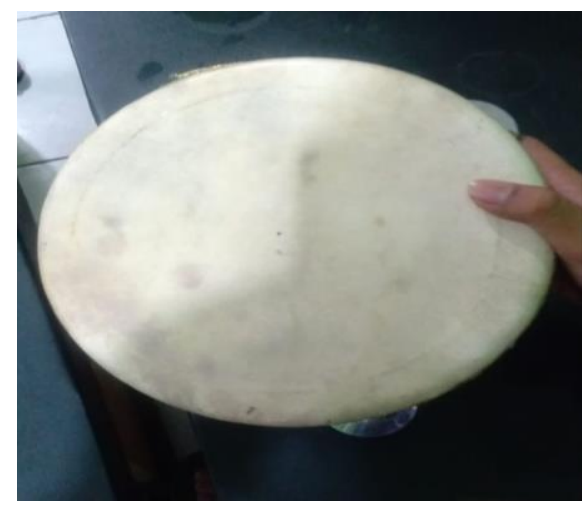

Tifa Cincang Atas

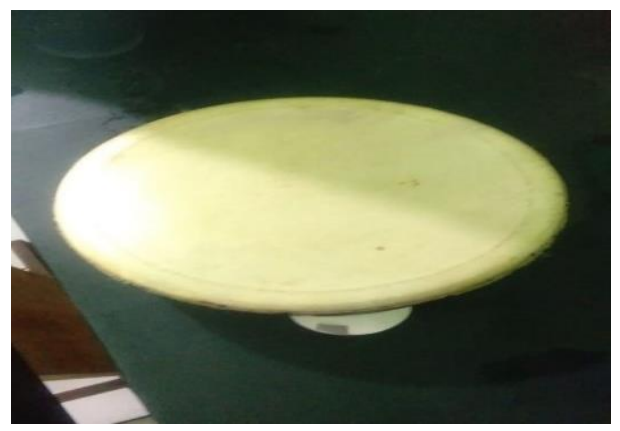

Tifa Cincang Bawah

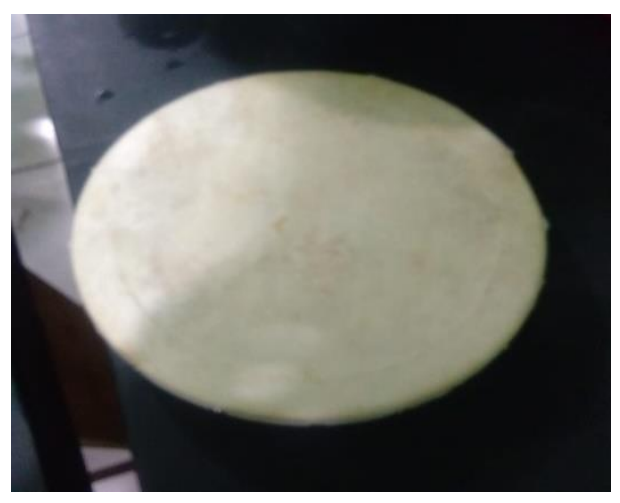

Tifa Ropol

Gambar 1. Jenis Tifa musik Hadroh Talake

(Foto: Lestari, 2019)

Sementara itu, instrumen musik terompet yang dalam hal ini sering disebut paduan terompet, terdiri dari beberapa gabungan alat musik tiup di antaranya terompet, horn, trombone, baritone dan bas tuba. Gambar 2 adalah nama-nama bagian dari alat music terompet yang disebutkan dari nomor urut 1 sampai dengan 11, yaitu: Mouthpiece, Lead pipe, Valve 1, Valve 2, Valve 3, Finger rings, Bell, Water key, Tuning slide, Finger rings, 3 rd valve slide, 2 nd valve slide dan 1st valve slide.

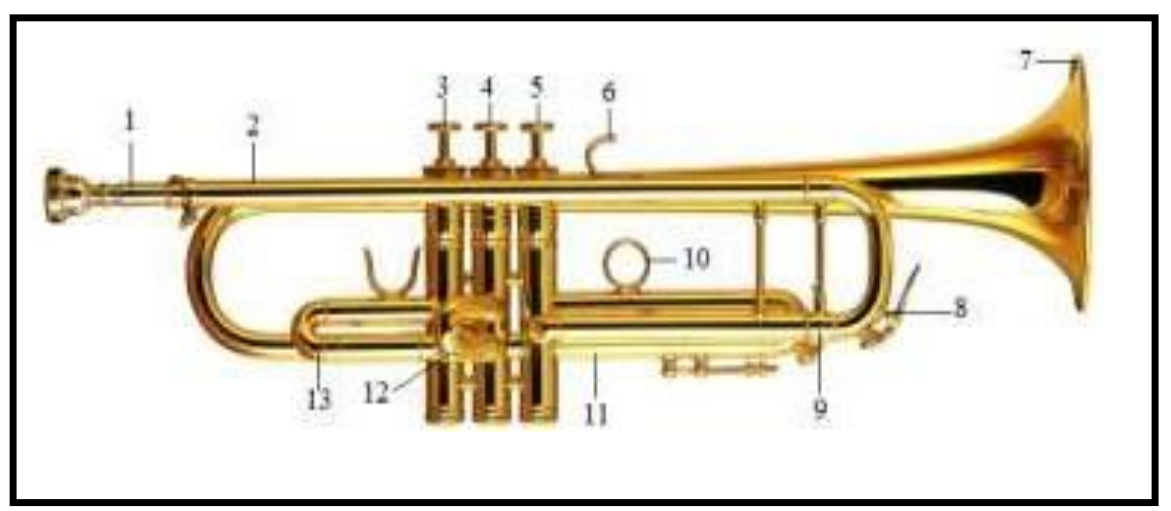

Gambar 2. Bagian-bagian alat music terompet (Foto: Gunawan, 2015) 
Teknik penjarian untuk seluruh instrumen tiup logam antara lain: terompet, horn, trombone, baritone dan bas tuba hampir sama, terutama bentuk nada-nada overtone series-nya. Gambar 3 adalah bentuk posisi penjarian pada instrumen terompet dan nada-nada yang dihasilkan. Pada kolom paling kiri dijelaskan nama nada, dan pada kolom paling kanan terdapat posisi penjarian. Kolom penjarian memiliki keterangan K1 yang berarti jari satu, K2 yang berarti jari dua, dan K3 yang berarti jari tiga. Titik bulat berwarna hitam adalah valve yang ditekan atau dipencet, sedangkan titik bulat berwarna putih adalah valve yang tidak dipencet atau dilepas.

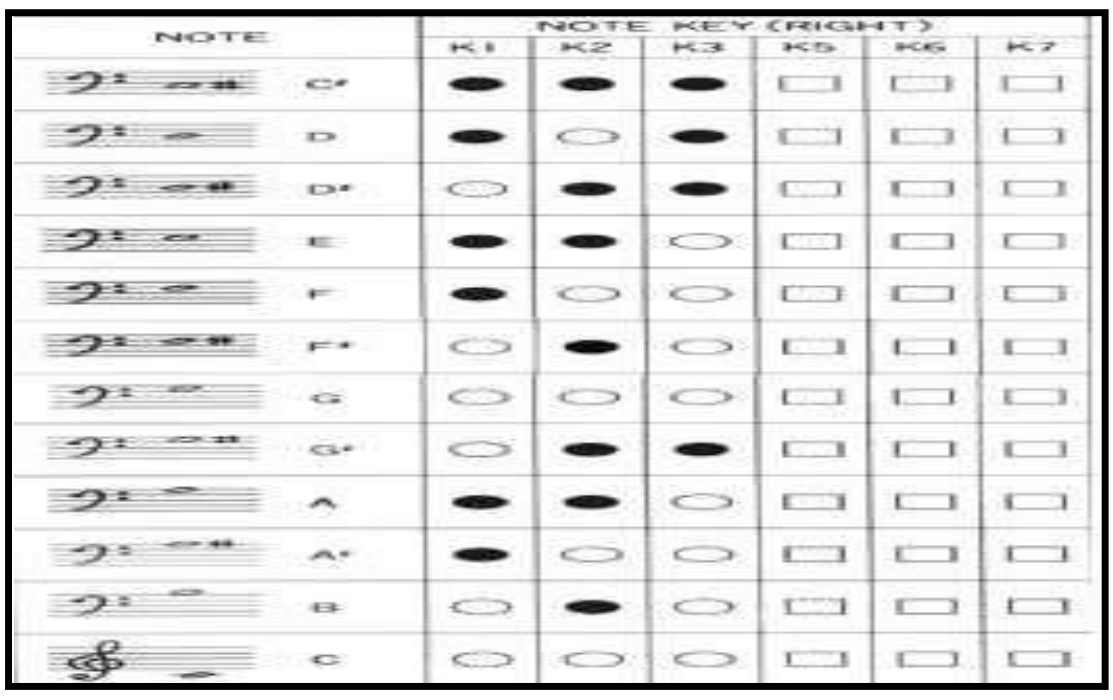

Gambar 3. Penjarian Pada Trompet (Sumber: Gunawan, 2015)

Analisis Bentuk Kolaborasi Musikal

\section{Shalawat Badriah}

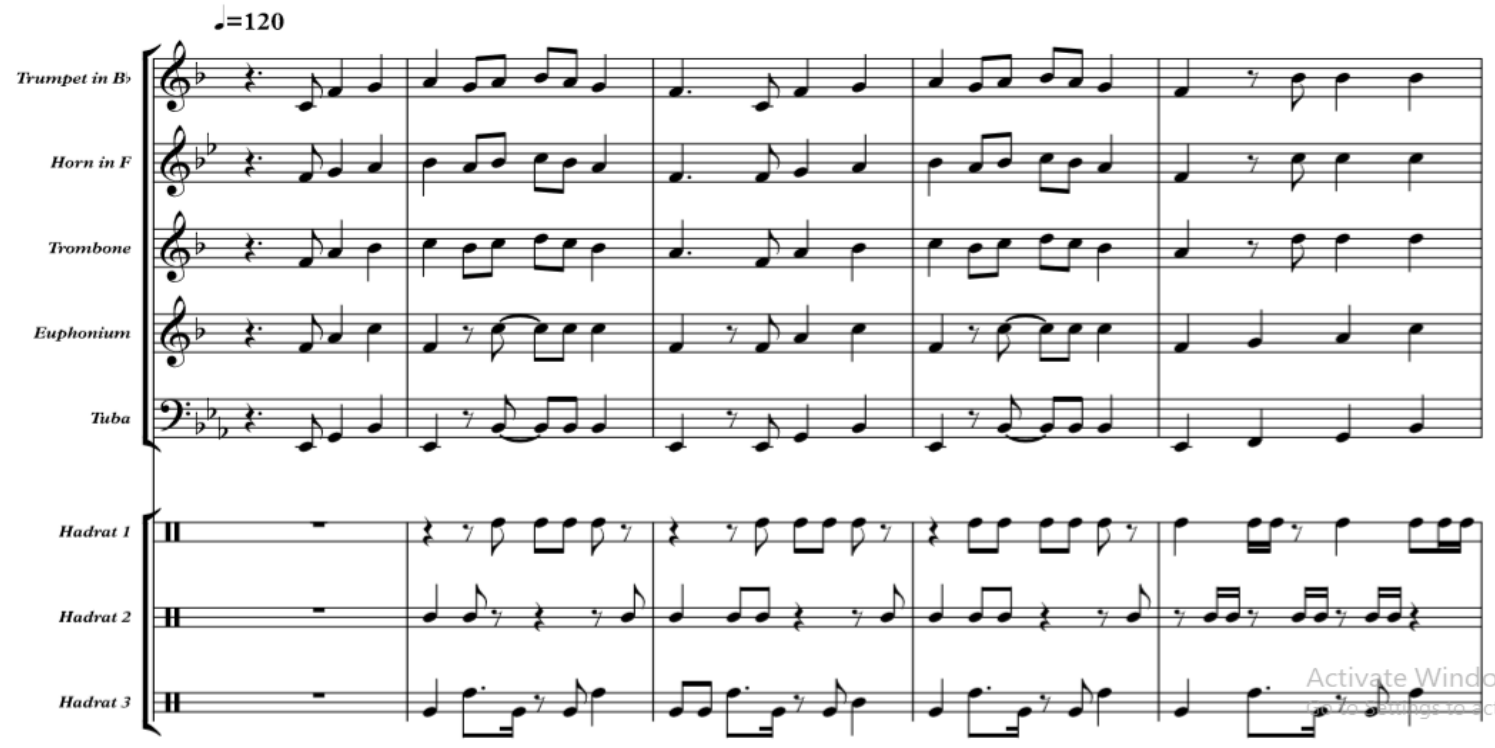

Gambar 4. Contoh Bagian Awal Komposisi Musik Shalawat Badriah

(Sumber: Lestari, 2019).

Gambar 4 adalah salah satu contoh komposisi musik shalawat badriah yang dikomposisikan oleh Leo Lorwens untuk kolaborasi musik trompet dengan hadroh yang dimainkan oleh para musisi Kristen 
dan Muslim di Ambon. Dalam analisis musik, beberapa unsur penting yang perlu dipahami adalah warna suara, irama, dan dinamika.

Warna suara (timbre) memiliki karakter bunyi yang membedakan bunyi satu dengan yang lainnya. Begitu pun dalam harmoni musik hadrah dan terompet. Dua jenis instrumen yang digabungkan menjadi sebuah komposisi dan membentuk sebuah harmoni pun melambangkan simbol kerukunan. Proses kolaborasi kedua instrument ini pun sudah sangat serasi ketika disatukan. Saat terompet memainkan lagu yang sudah diaransmen, kemudian musik hadrah dapat mengamati dan mendengar terlebih dahulu, kemudian mereka mengikuti atau secara tidak langsung mengiring paduan musik terompet melalui tempo dengan istilah yang sering disebut pukul lari. Istilah pukul lari saat ditelusuri maknanya, ternyata yang dimaksudkan adalah jamming yang artinya bermain musik secara bersamasama dan sifatnya spontan.

Pada hakekatnya, irama dapat dipahami sebagai gerak teratur yang mengikuti jalannya melodi. Namun irama dapat berjalan dengan sendirinya tanpa adanya melodi. Hal ini pun terjadi pada kolaborasi musik hadrah dan terompet. Irama merupakan gerak musik yang teratur serta tidak tampak dalam lagu namun dapat dirasakan setelah lagu itu dilantunkan. Variasi iringan hadrah dapat dikelompokkan ke dalam tiga macam pola ritmis yang berbeda dan digunakan pada saat saat tertentu dalam penyajian lagu. Menurut catatan lapangan, sebagai hasil wawancara yang dilakukan oleh peneliti, bentuk penyajian lagu hadrat bersifat fleksibel, artinya bisa diawali dengan instrument terompet, kemudian disusul dengan musik hadrah. Selain itu, hadrah Talake Waringin memiliki istilah-istilah yang khas untuk menyebut aspek-aspek musikal tertentu, seperti pukul lari, cincang, ropol, masuk dobol, dan ropol dobol. Hal itu karena musik hadroh Talake mempunyai 4 jenis tifa dengan pola ritmisnya masing-masing. Berdasarkan produksi suaranya, transkripsi ritmis pengiring dilambangkan dengan huruf "T" untuk bunyi "Tak", dan "D" untuk bunyi "Dung".

Dinamika bermusik adalah sistem tanda yang akan dimainkan untuk mengatur volume keras dan lembut suara. Dinamika pada paduan musik terompet dan musik tahuri biasanya diatur oleh komposer untuk menunjukkan bagaimana perasaan yang terkandung dalam sebuah karya, baik itu menggambarkan suasana riang, sedih, datar, dan sebagainya. Untuk volume musik hadrah dipengaruhi oleh besar kecilnya intensitas suara, jumlah suara, gema ruangan (resonansi), dan jumlah harmoni yang dimainkan. Besar kecilnya ukuran rebana sangat mempengaruhi suara yang dihasilkan. Semakin besar rebana, nada suara yang dihasilkan akan lebih rendah, begitupun sebaliknya.

\section{Peristiwa dan Wacana Kolaborasi Musikal}

Ampi Hidongoran, seorang Majelis Jemaat GPM Rehobot yang sejak awal pembentukan kolaborasi musik hadroh dan trompet dipercayakan oleh pihak gereja untuk mengkordinir seluruh proses bersama, menegaskan bahwa sejak awal kolaborasi ini bertujuan untuk merawat perdamaian. Menurut Hidongoran, inisiatif untuk melaksanakan kolaborasi musik hadroh dan trompet memang berdasarkan salah satu keputusan Persidangan Jemaat di tahun 2011 untuk meningkatkan hubungan persaudaraan dengan umat Muslim di wilayah Talake dan Waringin. Kedua wilayah ini merupakan wilayah pemukiman umat Muslim yang berdampingan dengan warga jemaat GPM Rehobot. Program ini kemudian diwujudkan dalam proses kerjasama antara pemuda gereja Rehobot dan remaja Masjid Talake-Waringin untuk menjaga keamanan dalam perayaan minggu Adventus dan Natal di tahun 2011. Pada saat itulah, basudara dari remaja masjid Talake-waringin, yang sebagian besar adalah para pemain musik hadroh, datang dengan membawa alat musik tifa atau rebana. Setelah warga jemaat selesai beribadah, mereka kemudian mengiring warga jemaat yang berjabat tangan dengan tabuhan tifa dan musik hadroh. Kemudian, paduan trompet yang baru selesai mengiringi peribadahan jemaat ikut bergabung dan secara spontan mereka membawakan lagu-lagu persaudaraan, seperti lagu gandong secara bersama-sama. Tampilan bersama dua komunitas musik dengan latar belakang agama dan materi musik yang berbeda, mampu menggugah suasana warga jemaat yang baru selesai beribadah. Dari sinilah dorongan untuk berkolaborasi demi merawat perdamaian antar masyarakat terbangun (Hidongoran, wawancara pribadi, 11 Agustus 2019). 
Kolaborasi musik ini berlanjut dengan agenda yang disepekati bersama bahwa pada setiap hari raya besar keagamaan Islam dan Kristen, seperti Natal dan Idul Fitri, atau Tahun Baru dan Hari raya Qurban atau Maulid Nabi Muhamad, kedua komunitas musik akan selalu tampil bersama. Opa Leo Lorwens, pelatih musik trompet, dengan pengalaman dan pengetahuan musikalitasnya, dipercaya untuk mengaransemen dan melatih. Proses latihan pun dijadwalkan sesuai dengan jadwal latihan paduan trompet, pada setiap hari Rabu, Kamis dan Sabtu. Tempat latihan berlangsung di gedung gereja lama Rehobot, yang telah dijadikan sebagai serba guna. Seiring dengan waktu, kolaborasi kedua kelompok musik kini mendapatkan apresiasi dari pemerintah dan masyarakat luas, sehingga mereka tidak sebatas tampil pada perayaan hari besar keagamaan, tetapi juga mendapatkan undangan dalam berbagai acara, seperti pelantikan gubernur, hari ulang Tahun TNI dan POLRI, dan berbagai acara resmi lainnya.

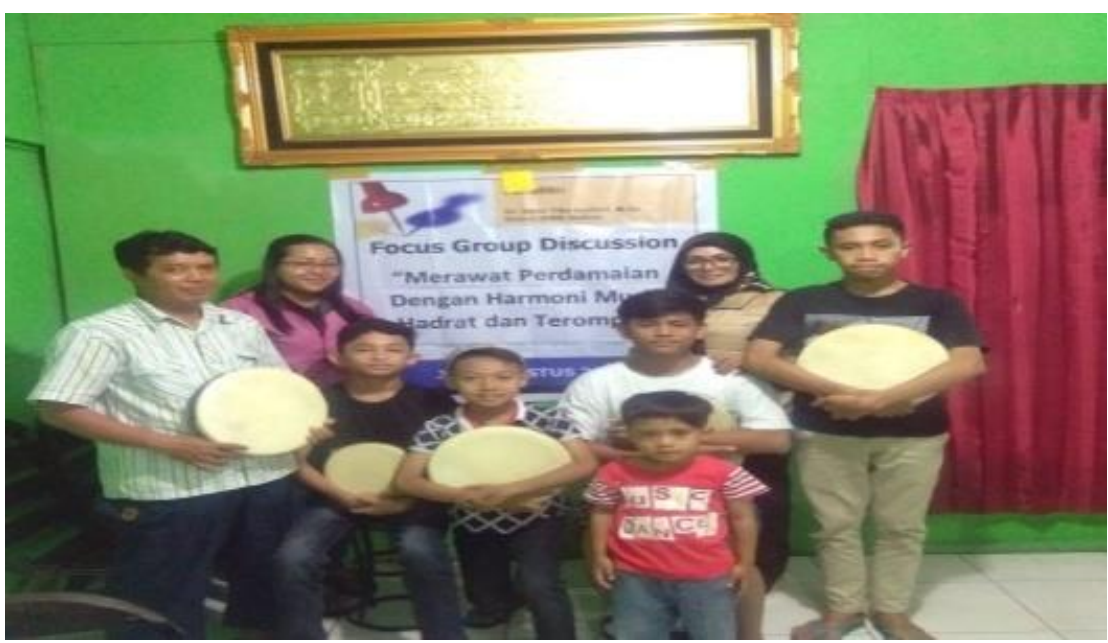

Gambar 5. Sebagian anggota komunitas musik hadroh Talake-Waringin

(Foto: Lestari, 2020)

\section{Kolaborasi Musik Mempraksiskan Kolaborasi Antar Umat Beragama}

Leo Lorwens, pelatih trumpet dan hadroh yang akrab disapa Opa Leo (71 Tahun) mengisahkan pengalamannya selama melatih kedua komunitas musik. Sebagai figur orang tua, Opa Leo selalu menegaskan pentingnya membangun harmoni dari dalam komunitas. Mereka mulai dengan saling berkenalan, saling mengerti dan saling membangun hubungan sebagai sesama saudara yang saling membantu. Menurut Opa Leo, pada setiap kali latihan, hal yang paling sulit adalah membangun harmoni musikal di antara kedua komunitas musisi dengan instrument musik yang berbeda. Paduan trompet yang terbiasa dengan latihan rutin, lebih cepat menangkap pola komposisi musik, sementara itu komunitas hadroh, masih tetap dengan pola musikalitasnya ketika bermain sendirian (Lorwens, wawancara pribadi, 12 Agustus 2019).

Dalam konteks perbedaan instrument musik dengan perbedaan karakteristik pemain maka yang terpenting adalah sikap penguasaan ego musikalitas. Masing-masing pemain sudah harus bermain mengikuti arahan patitur dengan menggunakan feeling musikal yang sama, sehingga kolaborasi ini bisa menciptakan suatu harmoni. Seiring waktu, dengan intensitas latihan bersama yang dibangun, maka rasa musikalitas di antara kedua kelompok musik dapat terbangun. Kemistri ini berkaitan dengan rasa musikalitas dari setiap pemain. Dengan demikian, ketika membawakan lagu apa pun, hanya dengan arahan sederhana dari pelatih mengenai bagain-bagian komposisi musik, kedua kelompok musik dapat tampil dengan baik. Menurut Opa Leo Lorwens, komposisi karya musik kebanyakan adalah musik-musik religious dari kedua agama, Islam dan Kristen, ada pula lagu-lagu nasional dan lagulagu persaudaraan di Maluku. Kolaborasi yang harmonis dari kedua kelompok musik ini menjadi suatu signifier (penanda) bahwa musik memang memiliki kekuatan merefleksikan suatu harmoni sosial di antara masyarakat. 
John M. O'Connell menyebutkan istilah harmoni yang sangat melekat dalam konsep teori musik dan domain antropologi merupakan salah satu ungkapan dalam skenario membangun harmoni sosial. Dalam teori musik, harmoni dihasilkan dari perpaduan nada-nada yang berbeda. Ini juga dapat menunjuk pada perpaduan identitas kultural yang berbeda dari setiap individu menjadi indentitas kultural kolektif dalam rangka mengupayakan kohesi sosial atau stabilitas sosial. Selain itu, Connell juga menyetujui teori Johan Galtung, bahwa musik memiliki kapasitas dalam merawat perdamaian dengan lebih empatik, dan tanpa kekerasan (O'Connell \& Castelo-Branco, 2010, p. 8).

John Paul Lederach menjelaskan contoh-contoh konkret peranan musik dalam upaya mewujudkan perdamaian di beberapa tempat. Lederach mengisahkan salah satu pengalamannya ketika menjadi keynote speaker dan delegasi untuk deklarasi perdamaian di Irlandia Utara pada tahun 1994, antara kelompok Partai Republik dan pendukung setia militer. Dalam acara tersebut sempat terjadi ketegangan antara kedua kubu. Panitia acara ini pun secara spontan menyela acara deklarasi dengan pertunjukan tari dan musik yang dibawakan oleh para pemuda gereja Katolik dan Protestan. Seorang penyanyi tradisi dari Irlandia, Paul Brady tampil dan membawakan lagu tradisi berjudul "The Island". Di bagian belakang panggung, tempat Brady bernyanyi itu terdapat suatu layar besar, yang digunakan untuk memutar rekaman konflik dan kekerasan yang terjadi di Irlandia selama 32 tahun. Banyak korban jiwa, anak-anak yang kehilangan orang tua dan tidak dapat bersekolah diperlihatkan. Dalam salah satu lirik lagu Bardy, dinyatakan bahwa, "violence is trying to carve tomorrow from a tombstone and is wasting our children's future for the worn-out dreams yesterday". Artinya, kekerasan adalah usaha untuk mengukir hari esok dengan batu nisan dan menyia-nyiakan masa depan anak-anak karena lelah memikirkan hari esok. Pertunjukan musik itu serentak membuat ratusan orang yang hadir dalam acara deklarasi terdiam. Banyak orang mengeluarkan sapu tangannya untuk menyeka air mata. Mendekati akhir pertunjukan, masing-masing kelompok yang bertentangan pun saling merangkul, dan meminta maaf atas segala kejadian, konflik dan kekerasan yang sudah merusak kehidupan dan masa depan mereka (Lederach, 2005).

Selain mengisahkan peranan musik dalam deklarasi perdamaian di Irlandia, Lederach juga menulis kisah yang hampir sama di negara yang berbeda, seperti di Afrika Selatan, Ghana dan Colombia. Dari kisah-kisah tersebut, Lederach (2005) secara tegas menyatakan:

Music, is seems, has the power to push things either in direction of greather violence or toward reconciliation... the concrete challenges of their enemy through song and words to become sane human beings. One could argue that a song changed a person and transformed our globe.

Musik tampaknya, memiliki kekuatan untuk mendorong hal-hal baik ke arah kekerasan yang lebih besar atau ke arah rekonsiliasi... tantangan konkret musuh mereka melalui lagu dan katakata untuk menjadi manusia yang baik. Orang dapat berargumen bahwa sebuah lagu mengubah seseorang dan mengubah dunia kita.

Menurut Defi Bin Umar (50 Tahun), kordinator musik hadroh, kolaborasi musik hadroh dan trompet juga memiliki kekuatan untuk mendorong integrasi sosial di tengah masyarakat, yang dimulai dari keluarga para pemain musik, kemudian lingkungan, dan seterusnya menjadi suatu pemberitaan bagi masyarakat luas. Ketika proses kolaborasi musik dengan latar belakang agama yang berbeda dilakukan, ada berbagai tantangan yang dihadapi. Menurut Ibu Defi Bin Umar, dari sebagaian keluarga dan komunitas Muslim di sekitar lingkungan Talake, ada yang menolak untuk membangun kolaborasi tersebut. Bagi kelompok yang menolak, alasan utamanya adalah karena musik hadroh merupakan musik religious umat Muslim, sama halnya dengan musik trompet. Menggabungkan keduanya sama dengan memaksakan kedua agama bergabung. Ibu Defi Bin Umar berusaha meyakinkan kelompok ini bahwa mereka tidak menjadi Kristen ketika membangun kolaborasi musik. Sebaliknya, mereka yang Kristen tidak akan menjadi Islam. Namun, dengan kolaborasi musik religious dari kedua komunitas agama yang berbeda, mereka secara bersama ingin mengkomunikasikan suatu pesan bahwa musik dan agama dapat berkolaborasi untuk membangun suatu harmoni sosial dan perdamaian (Umar, wawancara pribadi, 18 Agustus 2019). 
Tantangan yang serupa juga dihadapi oleh Opa Leo Lorwens di mana beberapa keluarga tidak ingin anak-anaknya terlibat dalam kolaborasi musik hadroh dan trompet. Alasannya yang paling mendasar adalah karena perbedaan agama. Selain itu, segregasi sosial yang makin menguat pasca konflik Maluku menimbulkan sikap tidak saling percaya antara dua komunitas masyarakat. Akan tetapi, Opa Leo Lorwens bersama anggota paduan trompetnya tetap konsisten dengan prinsip bahwa paduan trompet ini ada untuk memuji Tuhan, selain di rumah Ibadah, juga di tengah masyarakat untuk membangun dan perdamaian. Oleh karena itu, paduan trompet Orel ini tetap melakukan kolaborasi musik sebagai bagian dari suatu aktivitas sosial membangun jaringan persaudaraan demi merawat perdamaian di Maluku.

Arild Bergh menjelaskan bahwa musik memiliki kekuatan dalam transformasi konflik jika diposisikan sebagai suatu ativitas sosial. Dalam aktivitas sosialnya, musik berisikan sejumlah isu dan kepentingan sosiologis, seperti transformasi konflik, pengembangan jejaring sosial, hubungan kekuasan lintas ruang, komunikasi lintas budaya, dan konstruksi identitas kultural melalui penemuan kembali tradisi masa lampau (Bergh, 2015).

Karya dari kedua komunitas musik ini tidak serta-merta dapat membalikkan suatu kondisi dari berbagai peristiwa kekerasan dan konflik menjadi suatu keharmonisan dan kedamaian. Namun lebih daripada itu, melalui karya mereka yang bernilai estetis inilah, masyarakat luas yang tertarik untuk merajut perdamaian, dapat menelisiknya lewat karya seni yang mereka hasilkan. Karya seni menjadi saksi yang terus menghidupkan sejarah dan memori setiap individu atau kelompok, yang berdampak pada pembentukkan identitas sosial. Dalam hal ini, Ralph Waldo Emerson menegaskan bahwa seorang seniman telah berjuang keras untuk menjadi subjek yang mengetahui, pelaku, dan pemberi pesan (Stephen J. \& D. Engles, 2011).

Upaya merawat perdamaian melalui proses transformasi konflik yang dilakukan dengan pertunjukan musik memang bukanlah sesuatu yang mudah. John Paul Lederach menilai upaya ini sebagai sejumlah usaha yang kompleks dan sulit dipercaya. Namun musisi yang terlibat sekaligus sebagai aktivis perdamaian (peacebuilder) disarankan untuk tidak menolak atau lari meninggalkan perjuangan yang kompleks tersebut. Perdamaian yang diupayakan lewat proses transformasi konflik merupakan suatu perjuangan berharga karena komplesitasnya perjuangan tersebut.

Penglibatan musik dalam merawat perdamaian disebutkan oleh Mc.Donald dan Diamond sebagai suatu bentuk diplomasi kreatif. Diplomasi kreatif memberikan ruang yang lebar bagi para seniman, termasuk musisi untuk mengkreasikan karya-karya musik mereka dalam rangka menopang upaya membangun perdamaian dalam suatu wilayah yang sedang atau memiliki potensi konflik. Melalui musik, pesan-pesan persaudaraan dan perdamaian terus dikomunikasikan kepada semua masyarakat. Mereka dilibatkan bernyanyi dan bermusik dalam alunan musik yang mendiplomasikan perdamaian di tengan masyarakat. Peranan musik dalam upaya perdamaian mengindikasikan bahwa musik bukan sekedar bunyi tanpa makna, lebih daripada itu, musik pun dapat menjadi bahasa universal, bahasa emosional yang menggerakan perilaku manusia (Clements, 2005). Sekalipun merupakan bahasa universal, diplomasi perdamaian melalui musik harus dilakukan di dalam konteks budaya masyarakat pemilik musik. Hal ini dimaksudkan agar pesan-pesan perdamaian yang dikomunikasikan di dalam komponen budaya masyarakat pemilik musik itu mudah dipahami.

Komposisi musik yang dibuat oleh Opa Leo Lorwens, sekalipun menggunakan lagu-lagu bernuansa keagamaan dengan karakteristik padang gurun, misalnya lagu-lagu Islamis, atau karakteristik Barat untuk lagu-lagu Kristen, selalu dibuat secara sederhana agar bisa diterima oleh penikmat musik di Maluku. Karya musik yang dilakukan oleh Opa Leo bersama dengan komunitas musik trompet dan hadroh merupakan suatu proses komunikasi sekaligus pembelajaran harmoni hidup antar umat beragama di Maluku sebagai sesama orang basudara. Menurut Parihala, dkk. (2019b) pendidikan hidup orang basudara merupakan basis merawat perdamaian di Maluku. 


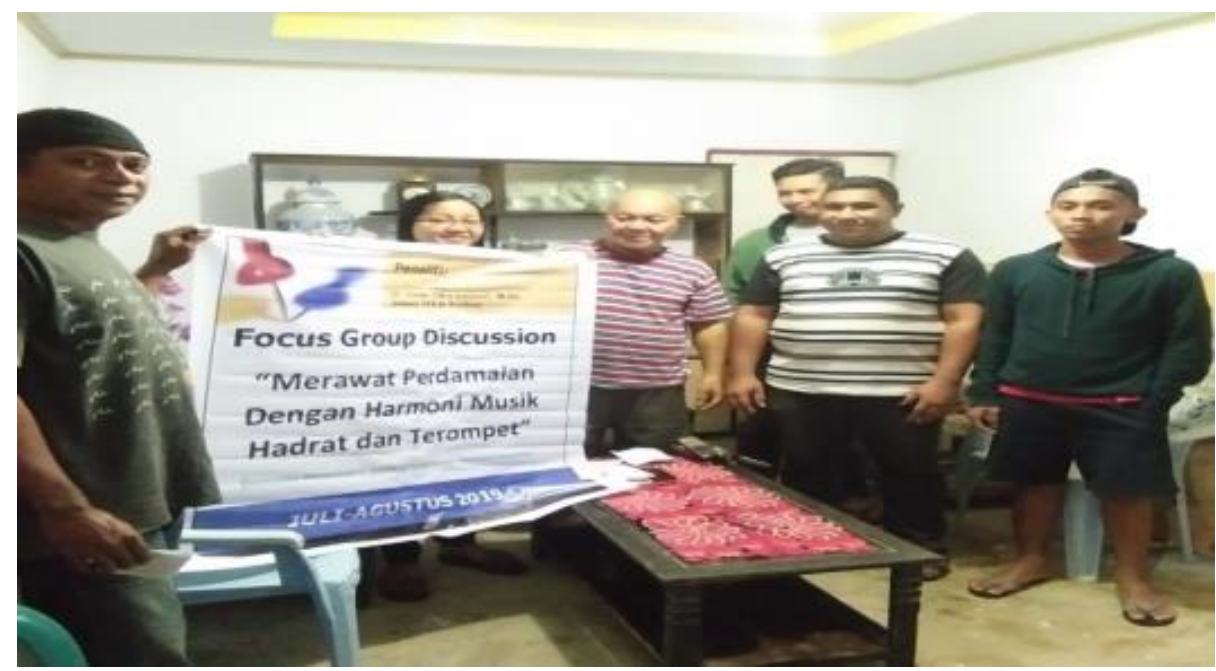

Gambar 6. Bersama Opa Leo Lorwens dan sebagai komunitas Trompet

(Foto: Lestari, 2020)

Harmoni musik hadroh dan trompet memperlihatkan suatu corak baru dalam membangun dan merawat perdamaian, yakni dapat dilakukan dengan cara-cara kreatif, antara lain melalui kolaborasi musikal, dan tidak selalu dengan pendekatan yang represif. Para musisi yang melakukan kolaborasi musik dengan latar belakang agama yang berbeda dapat mengkomunikasikan bahwa seperti harmoni musik yang tercipta dari keberagaman nada dan unsur musikal, demikian juga agama-agama di dalam keberagaman dan keunikannya, mampu membangun harmoni hidup.

\section{Kesimpulan}

Kolaborasi musik hadroh dan trompet untuk merawat harmoni sosial antar umat beragama bukan suatu peristiwa musikal yang berdiri sendiri.Peristiwa musikalitas ini berangkat dari suatu realitas yang berbeda, tetapi terikat dalam konotasi makna, yaitu pengalaman konflik Maluku dan upaya merawat perdamaian yang telah terbangun.Konflik Maluku merupakan suatu realitas metabahasa atau metamusik, yang transendent dan distinct dari peristiwa musikal kolaborasi musik hadroh dan trompet. Dari analisis ini ditemukan bahwa material fisik dan non fisik musik hadroh dan trumpet memiliki perbedaan. Namun, ketika perbedaan itu dikolaborasikan secara kreatif dan harmonis, didukung oleh kesediaan dan kemauan berlatih para musisi dengan latar belakang yang berbeda, maka hamonisasi dapat terbangun. Harmoni musik yang terbangun dari perbedaan materi musikal menuntun pada penciptaan harmoni sosial dari penyatuan identitas sosial-keagamaan komunitas masyarakat yang berbeda.

Kolaborasi musik hadroh dan trumpet telah mengkomunikasikan secara mendalam bagi masyarakat untuk merawat harmoni dan perdamaian. Sebagaimana musik hadroh dan trumpet yang memiliki perbedaan material musik dapat dikolaborasikan untuk menciptakan suatu harmonisasi musik yang indah, maka perbedaan di dalam masyarakat merupakan potensi untuk membangun harmoni sosial yang damai. Seperti harmoni musik itu indah, maka damai di dalam harmoni sosial antara masyarakat adalah suatu keindahan. 


\section{Referensi}

Al Qurtuby, S. (2013). Peacebuilding in Indonesia: Christian-Muslim Alliances in Ambon Island. Islam and Christian-Muslim Relations, 24(3), 349-367. https://doi.org/10.1080/09596410.2013.785091

Armando, A. (2019). Kontestasi dan Negosiasi Kepentingan dalam Implementasi Sistem Siaran Jaringan Televisi di Indonesia. Jurnal Komunikasi, 14(1), 41-60. https://doi.org/10.20885/komunikasi.vol14.iss1.art3

Bergh, A. (2015). Emotions in motion: transforming conflict and music. In Music and the Mind. https://doi.org/10.1093/acprof:osobl/9780199581566.003.0018

Bergh, A., \& Sloboda, J. (2010). Music and Art in Conflict Transformation: A Review. Music and Arts in Action, 2(2), $1-16$.

Dandirwalu, R. (2014). Totem Ambon Manise: Membongkar Segregasi Teritorial Berbasis Agama di Kota Ambon. Antropologi Indonesia; Indonesian Journal of Social and Cultural Anthropology, 35(1), 33.

Diah Kusumaningrum. (2017). Belajar dari rekonsiliasi sehari-hari di Maluku. In Ihsan Ali-Fauzi (Ed.), Ketika Agama Bawa Damai, Bukan Perang. Jakarta: PUSAD Paramadina.

Ernas, S. (2018). Dari Konflik ke Integrasi Sosial: Pelajaran dari Ambon-Maluku. International Journal of Islamic Thought, 14(1), 99-111. https://doi.org/10.24035/ijit.14.2018.009

Fairclough, N. (2013). Critical Discourse Analysis. Old Tappan: Taylor and Francis.

Gunawan, Y. P. (2015). Analisis Fungsi Dan Kesulitan Memainkan Alat Musik Trumpet Pada Mahasiswa Ukm Marching Band UNNES. Universitas Negeri Semarang.

Harnett Stephen J. \& Jeremy D. Engles. (2011). Melodi di Tengah Perang. In Norman K Denzin \& Y. S. Lincoln (Eds.), The Sage Book of Qualitative Research 2 (3rd ed.). Yogyakarta: Pustaka Pelajar.

Iwamony, R., Gaspersz, S., \& Souisa, N. (2019). To embrace and be embraced: School pela in post-conflict ambon. Studies in Interreligious Dialogue. https://doi.org/10.2143/SID.29.1.3286456

Kalay, N. S. (2020). Segregasi Pasca Konflik, Communal Discourse dan Material Culture Bagi Penguatan Agama dan Kebangsaan di Maluku. ARUMBAE: Jurnal Ilmiah Teologi Dan Studi Agama, 2(1), 46-58.

Kevin P Clements. (2005). Peran organisasi regional dan organisasi masyarakat sipil dalam mencegah dan mengatasi konflik di wilayah Asia Pasifik. In D. F. Anwar, H. Bouvier, \& G. Smith (Eds.), Konflik Kekerasan Internal. Jakarta: Buku Obor.

Lalopua, Y. P., \& Iwamony, R. (2019). TEOLOGI PELA: Studi Teologi Kontekstual di Negeri Abubu dan Negeri Tengah-Tengah. ARUMBAE: Jurnal Ilmiah Teologi Dan Studi Agama. https://doi.org/10.37429/arumbae.v1i1.183

Lambang Trijono. (2001). Keluar Dari Kemelut Maluku. Yogyakarta: Pustaka Pelajar.

Lederach, J. P. (2005). The Moral Imagination. In The Moral Imagination: The Art and Soul of Building Peace. https://doi.org/10.1093/0195174542.001.0001

Lestari, D. T. (2017). Peran Musik Sebagai Salah Satu Media Perdamaian. Institut Seni Indonesia (ISI) Surakarta.

Lestari, D. T. (2019). Menggali Falsafah Hidop Orang Basudara dari Melodi Bakubae (Perdamaian)-Lagu Gandong di Maluku. Melayu Arts and Performance Journal, 2(1), 15-25.

Lestari, D. T., \& Parihala, Y. (2020). Merawat Damai Antar Umat Beragama Melalui Memori Kolektif dan Identitas Kultural Masyarakat Maluku. Hanifiya: Jurnal Studi Agama-Agama, 3(1), 43-54. https://doi.org/10.15575/hanifiya.v3i1.8697

Lindawaty, D. S. (2016). Konflik Ambon: Kajian Terhadap Beberapa Akar Permasalahan dan Solusinya. Jurnal Politica Dinamika Masalah Politik Dalam Negeri Dan Hubungan Internasional, 2(2).

Mannitz, S. (2017). The cultural dimension of peace: Decentralization and reconciliation in Indonesia. Peacebuilding, 5(3), 344-345. https://doi.org/10.1080/21647259.2017.1324369

O'Connell, J. M., \& Castelo-Branco, S. E. S. (2010). Music and conflict. In Music and Conflict. https://doi.org/10.5860/choice.48-3769

Palmer, B. (2014). Migrasi dan identitas: perantau Buton yang kembali ke Buton setelah konflik Maluku 1999-2002. Antropologi Indonesia.

Parihala, Y., Samson, R. A., \& Tika Lestari, D. (2019). The Education of “Orang Basudara": The Development of Multicultural Education in the Higher Education of Maluku Indonesian Christian University and Its Contribution to Maintain Peace in Maluku. Proceedings of the International Conference on Religion and Public Civilization (ICRPC 2018). https://doi.org/10.2991/icrpc-18.2019.6

Parihala, Y., \& Sapteno, K. (2020). Dari Kesaksian Iman ke Simbiosis Agama: Meninjau Konsep Dialog Calvin E. Shenk Bagi Perjumpaan Islam-Kristen di Maluku. Religious: Jurnal Studi Agama-Agama Dan Lintas Budaya, 4(2), 103-114. https://doi.org/10.15575/rjsalb.v4i2.8250

Sabandar, D. F., Saimima, J. R., \& Parihala, Y. (2020). Agama untuk Perdamaian Berdasarkan Interpretasi Lukas 12:49-53 dari Perspektif Teologi Religionum. ARUMBAE: Jurnal Ilmiah Teologi Dan Studi Agama, 2(1), 110- 
121. https://doi.org/10.37429/arumbae.v2i1.416

Sholikha, S. M. (2018). Pengaruh Kesenian Hadrah Al-Banjaridalam Upaya Meningkatkan Kecerdasan Spiritual (SQ) Remaja Di Desa Konang Kecamatan Glagah Kabupaten Lamongan. Universitas Islam Negeri Sunan Ampel Surabaya.

T. Pariela. (2008). Damai di Maluku. Salatiga: Satyawacana University Press.

Tahalea, M., Tondobala, L., \& Mastutie, F. (2016). Museum Perdamaian Maluku Di Ambon “Eco-design for Respect the Spirit and Culture of Moluccan." Daseng: Jurnal Arsitektur, 5(1), 66-77.

Tika Lestari, D. (2019). Religious Conflict Transformation through Collective Memory and the Role of Local Music. Proceedings of the International Conference on Religion and Public Civilization (ICRPC 2018). https://doi.org/10.2991/icrpc-18.2019.22

(C) 2020 by the authors. Submitted for possible open access publication under the terms and conditions of the Creative Commons Attribution (CC BY SA) license (https://creativecommons.org/licenses/by-sa/3.0/). 